\title{
AS ORDENS DE DOCUMENTOS, AS ORDENS DE ATIVIDADES E AS ORDENS DE INFORMAÇÕES*
}

\author{
LAS ÓRDENES DE DOCUMENTOS, LAS ÓRDENES DE ACTIVIDADES Y LAS ÓRDENES DE INFORMACIÓN \\ THE ORDERS OF DOCUMENTS, THE ORDERS OF ACTIVITY, AND THE ORDERS OF INFORMATION \\ Charles Bazerman** \\ University of California, Santa Barbara - UCSB, US
}

\begin{abstract}
RESUMO: Argumento neste artigo, da perspectiva de um estudioso da escrita e do letramento, que a informação humanamente utilizável tem sido (e provavelmente continuará a ser no futuro previsível) ligada a textos ou documentos humanos, ou seja, a artefatos feitos pelo homem, utilizando representações letradas, gráficas, em áudio ou multimídia as quais inserem informações relativas às atividades humanas e pensamentos. Enquanto concluímos a conversão de tecnologias mais antigas de armazenamento de informações baseadas em textos físicos, utilizados diretamente nas atividades reconhecíveis para inscrição digital, acesso, armazenamento e entrega de informações, estamos diante de escolhas que tanto podem homogeneizar informações como podem manter a visibilidade de documentos humanos (tanto materiais quanto virtuais), as situações das quais emergem e as situações em que eles serão utilizados, após acessados. à medida que desenvolvemos ferramentas, sistemas e conceitos para juntar peças muito heterogêneas inseridas em circunstâncias também heterogêneas, precisamos desenvolver ferramentas, sistemas e conceitos para ver as informações em suas circunstâncias particulares de uso.

PALAVRAS-CHAVE: gênero discursivo; meio digital; sistema de atividades.
\end{abstract}

RESUMEN: Argumento en este artículo, de la perspectiva de un estudioso de la escritura y de la literacidad, que la información humanamente utilizable ha sido (y probablemente continuará a ser en el futuro previsible) vinculada a textos o documentos humanos, o sea, a artefactos hechos por el hombre, utilizando representaciones letradas, gráficas, en audio o multimedia las cuales insieren informaciones relativas a las actividades humanas y pensamientos. Mientras concluimos la conversión de tecnologías más antiguas de almacenamiento de informaciones basadas en textos físicos, utilizados directamente en las actividades reconocibles para inscripción digital, acceso, almacenamiento y entrega de informaciones, estamos delante de elecciones que tanto pueden homogeneizar informaciones como mantener la visibilidad de documentos humanos (tanto materiales cuanto virtuales), las situaciones de las cuales emergen y las situaciones en que ellos serán utilizados, después de accesados. A medida que desarrollamos herramientas, sistemas y conceptos para unir piezas muy heterogéneas inseridas en circunstancias también heterogéneas, precisamos desarrollar herramientas, sistemas y conceptos para ver las informaciones en sus circunstancias particulares de uso. PALABRAS-CLAVE: género discursivo; medio digital; sistema de actividades.

ABSTRACT: In this article I will argue, from the perspective of a scholar of writing and literacy, that information has been (and will likely continue to be for the foreseeable future) tied to human texts—created, organized, circulated, and used within human activities. As we complete the conversion from older technologies of information storage based on the physical texts used directly within recognizable activities to digital inscription, storage, access and delivery of information, we are faced with choices that can either homogenize information or maintain visibility of human documents (whether material or virtual), the situations from which they arose, and the situations in which they will be used once accessed. As we develop tools, systems, and concepts to draw together more heterogeneous pieces from more heterogeneous circumstances, we also need to develop tools, systems and concepts to see information in its particular circumstances of use.

KEYWORDS: discourse genre; digital medium; system of activities.

\section{UMA ANEDOTA PREFACIAL}

Há doze anos, publiquei um estudo sobre os trabalhos de Edison em pesquisa, desenvolvimento e comercialização de luz e energia elétrica (BAZERMAN, 1999a). Nele, examinei os vários tipos de documentos produzidos como parte de diferentes sistemas de atividade - de pedidos de patentes e processos judiciais a entrevistas de jornais, de notas de laboratório a relatórios de acionistas, de cartas pessoais sobre estratégia a artigos científicos e relatórios de testes técnicos. Cada um desses documentos tomou forma em gêneros que se desenvolveram em sistemas sociais que mudaram historicamente. Cada um desses

\footnotetext{
* Tradução de Alana Driziê Gonzatti dos Santos. Texto proferido na mesa-redonda intitulada "Gênero textual/letramento, ciência e tecnologia” por ocasião do VI Simpósio Internacional de Estudos de Gêneros Textuais - VI SIGET, realizado na Universidade Federal do Rio Grande do Norte, Brasil, no período de 16 a 19 de agosto de 2011. Foi publicado, anteriormente, no periódico Archival Science, v. 12, n. 4, p 377-388, dez. 2012.

***Eail: bazerman@education.ucsb.edu.
} 
documentos também continha tipos específicos de informações que ajudaram a realizar o trabalho de financiar, proteger juridicamente, validar tecnicamente, produzir, publicar e distribuir comercialmente o sistema de energia elétrica complexa.

Logo depois da publicação do meu livro, um parecerista questionou o modo como eu caracterizei os regimes de trabalho no laboratório Menlo Park, em referência a um argumento feito por mim sobre a forma como as notas eram usadas para coordenar o trabalho de pesquisa da equipe de invenção e o trabalho legal/burocrático do escritório durante o outono de 1878. Esse parecerista alegou que o escritório ficava em um edifício separado. Eu tinha certeza de que os escritórios do prédio separado não tinham sido ocupados até alguns meses depois, mas como eu poderia confirmar isso? Embora algumas das fontes de autoridade primária ou secundária tenham mencionado a construção desse escritório, nenhuma especificou a data de conclusão e ocupação. Tendo trabalhado com os 97 rolos de microfilme nas Partes I e II dos trabalhos de Edison e muitos outros arquivos relacionados durante uma década, eu estava familiarizado com os registros que estavam disponíveis e o que estes poderiam conter. Além disso, os arquivistas do projeto Edison tinham organizado bem os materiais e desenvolvido excelentes localizadores, então fui diretamente para os registros de negócios do Menlo Park de 1879 (começando do rolo 50, quadro 487). Rapidamente encontrei estimativas e acordos para os trabalhos de carpintaria do novo escritório de janeiro e fevereiro de 1879, e depois os cadernos que estudei, confirmando minha afirmação original (EDISON, 1985, 1987).

Esta é uma história característica do trabalho de arquivo acadêmico do tipo analisado por Yakel e Torres (2003) no qual um estudioso conhece a história e os arquivos e tem a ajuda de arquivistas capazes que catalogaram, indexaram e organizaram os materiais disponíveis. Frente ao trabalho dos arquivistas, o que provocou a demora em eu me localizar e dar sentido à informação? Primeiramente, eu precisava de um conceito sobre que tipo de informação poderia existir para que pudesse contar como prova, o que dependia de conhecer os diferentes tipos de documentos ou gêneros contidos nos arquivos e os tipos de informação associadas a cada um dos gêneros. Eu também tinha de ter alguma ideia dos tipos de atividades de vários grupos de pessoas em épocas diferentes e como essas atividades poderiam deixar vestígios documentais. Eu também precisava confiar e entender como os arquivistas organizaram e indexaram o material e a relação dos números de índice para arquivos numerados e bobinas de microfilmes e quadros. Eu precisava entender todos esses princípios de organização para localizar as provas e tirar uma conclusão que não estivesse explicitamente declarada em nenhum documento.

Como escritor, produzo documentos, documentos que geralmente contêm informações - às vezes, eu produzi novas informações em minhas próprias investigações e, por vezes, relatos para dar sentido à informação que eu obtive em outro local - para realizar várias tarefas em minha vida, seja para fazer uma solicitação à minha companhia de seguros seja para defender teorias de práticas sociais de escrita. Em minha prática pedagógica, ajudo os alunos a localizar, utilizar e interpretar informações para que possam escrever de forma mais eficaz - especialmente em um contexto acadêmico, onde eles estão cercados por informações de suas disciplinas, bibliotecas e suas novas indagações. No meu trabalho e no trabalho dos meus alunos, regularmente, entramos em contato com informação disponibilizada e ordenada em acervos físicos e virtuais, de modo que as ordens de informação que fazemos na nossa escrita, os nossos enunciados, sejam dependentes e interativas em relação às ordens criadas nos sistemas de biblioteconomia. No início de minha carreira, antes da disseminação dos recursos digitais, uma longa experiência educacional e profissional era necessária para aprender a se movimentar nessas várias ordens e criar novas ordens. Como aluno, fui apresentado à organização de coleções e ferramentas de indexação, mas só depois de ter trabalhado em muitos projetos é que eu pude obter, de forma eficiente, o que eu precisava e pude imaginar o que poderia estar lá que eu poderia querer e formular hipóteses que estariam embasadas pelas informações disponíveis. No entanto, continuei a ter pistas falsas, buscas fracassadas e momentos de perplexidade em que consultei outros usuários experientes, estudiosos e profissionais de biblioteconomia. Às vezes, a única conclusão a que eu poderia chegar era a de que a informação que eu queria simplesmente não estaria lá ou não poderia ser acessada. Além disso, cada vez que entrava em uma nova área de investigação, eu precisava 
de algum tempo para me familiarizar com os recursos pertinentes e os princípios de ordenação específicos daquela área. Tão ordenada quanto podemos tornar a informação e tão visíveis quanto poderíamos fazer as ordens, em última análise, nós precisamos de síntese humana, hipóteses e criatividade para dar sentido a tudo isso. Na verdade, precisamos fornecer os materiais para dar sentido aos processos humanos.

\section{UM BREVE HISTÓRICO DO CONHECIMENTO}

A produção e transmissão do conhecimento foram, desde o princípio, ligadas à ação comunicativa humana e organizadas em sistemas sociais que conduzem adiante as ações e atividades. Mesmo que os processos de comunicação tenham sido menos ligados a circunstâncias sociais imediatas, eles têm proporcionado novos tipos de relações sociais e circunstâncias comunicativas que mantêm seu caráter social e sua funcionalidade. Em sociedades não letradas, o conhecimento é produzido diariamente em informes orais sobre comida e ameaças, pedidos de ajuda, diretrizes para uma ação coordenada, relatos de relações humanas, e assim por diante. Em cada tipo de conversa, as pessoas informam-se sobre diferentes objetos, estados de coisas, obrigações. Tal conhecimento, a fim de ser mais duradouro do que a alteração das circunstâncias dos enunciados e das incertezas da memória, deve mover-se de gêneros espontâneos falados para afirmações mais ritualizadas ligadas a ocasiões estabilizadas de performances, tais como as canções dos griôs e bardos que usam dispositivos mnemônicos para recordar e recriar histórias. Designs arquitetônicos, tais como monumentos e eixos de pedras, também podem instigar e estabilizar a memória assim como elementos gráficos.

A invenção do letramento foi também a invenção da informação escrita. De fato, a transcrição da informação foi o elemento propulsor da invenção da escrita e do seu desenvolvimento, começando com os tipos de registros agrícolas, inicialmente capturados em seixos de argila impressos no exterior de envelopes de argila (SCHMANDT-BESSERAT, 1992). Em pouco tempo, tabuletas de argila continham muitos tipos de documentos econômicos, governamentais e legais, armazenadas em Casas de Tabuletas mantidas pelo governo. Os registros incluíam leis, rolos de impostos, censo da população, forças militares e outros registros que apoiavam na governança. Mesmo nesses primeiros exemplos, vemos a conjunção de vários tipos de ordens dispostas em torno da informação e a conexão em que as informações se situavam: textos materiais localizados em coleções organizadas, textos como enunciados simbólicos reconhecíveis em gêneros, conhecimentos, domínios de conhecimento, seres humanos escrevendo e lendo como parte de outros tipos de atividades para as quais a atividade letrada é instrumental. Visto que o conhecimento para essas atividades era de uso persistente e duradouro, essas coleções de informação gravadas precisavam ser mantidas e encontradas para referência posterior.

Escrever, com isso, trouxe novas formas de registrar o conhecimento em sinais e listas de bens, pessoas e eventos, então inscritas em objetos sobre a sua propriedade, autoridade ou significado (SCHMANDTBESSERAT, 2007). Os eventos tornaram-se imortalizados na descrição e transcrição de discursos e odes (HAVELOCK, 1963). Leis foram promulgadas, copiadas e exibidas em todos os reinos (GOODY, 1986). Cartas proliferaram-se em gêneros de negócio, governança, amizade e filiação (BAZERMAN, 1999b). Cada tipo de texto continha tipos específicos de conhecimento. E aqueles, familiarizados com textos, tornaram-se hábeis em localizar o conhecimento de que precisavam, além de comparar e agregar vários relatos. Inseridos em domínios específicos de prática, o conhecimento poderia ser estabilizado, separado e avaliado, visto que o conhecimento tinha aumentado a autoridade. Todos os profissionais experientes deveriam estar familiarizados com um cânone de textos de autoridade, seja de retórica, astronomia, lei ou comércio. Educação significava familiarizar os alunos com o corpo de textos que continha o conhecimento fundamental das áreas de prática, orientar como esses textos poderiam ser aplicados em circunstâncias concretas e, talvez (mas nem sempre), como esses textos poderiam ser avaliados e produzidos. Textos oficiais foram amplamente copiados, distribuídos e preservados, apesar da despesa e da inconveniência. 
Textos que não se tornaram essenciais para sistemas sociais vibrantes existiram em poucas e dispersas cópias e, por vezes, desapareceram.

Com a imprensa, a facilidade de multiplicação de cópias significava um maior número de pontos de referência para ser compartilhado entre os especialistas e conhecimentos mais complexos e múltiplos poderiam ser aplicados em comunidades de prática. Essa diversidade de textos disponíveis permitiu mais comparações entre mais pessoas e mais partilha na avaliação e na construção de textos sobre o conhecimento. A agregação substancial foi possível, indo além dos poucos primeiros centros de aprendizagem, como Alexandria, Córdoba, Bolonha ou a corte imperial chinesa. A diminuição dos custos de impressão e papel aumentou a colaboração e a correção mútua, promoveu sociedades e periódicos, criou as correspondências e a discussão sobre textos compartilhados. Vários locais de produção de conhecimento concorrentes surgiram bem como uma República de Letras internacional partilhando os resultados de seus trabalhos (EISENSTEIN, 1979). A esfera pública cresceu com a mídia e os mercados cresceram para a transmissão de informação de negócios na imprensa comercial (BAZERMAN; ROGERS, 2008 a, 2008b). Instituições dedicadas à produção de informação, tais como universidades, academias e institutos de pesquisa nacionais cresceram assim como as tentativas de tornar o conhecimento amplamente disponível por meio de enciclopédias e da educação da classe operária.

\section{ARMAZENAMENTO DE TEXTOS E ACESSO AO CONHECIMENTO}

Com base em que princípios esses textos produzidos no âmbito dessas atividades e instituições deveriam ser organizados e indexados? Este problema formou a base do trabalho das ciências da informação e da biblioteconomia e muitas soluções foram encontradas ao longo dos milênios, começando por critérios de armazenamento físico, tais como o tamanho dos rolos ou códices, e evoluindo com os critérios de domínio de conhecimento de sistemas de indexação dos séculos XIX e XX, tais como o sistema Decimal de Dewey (1947) e o da Biblioteca do Congresso. Múltiplas formas de indexação, como as incorporadas em catálogos de cartões com entradas separadas para o título, autor, assunto e número de prateleira promoveram formas alternativas de localização do tex to em prateleiras de acordo com diferentes princípios ordenadores. Como as redes de citação passaram a ser entendidas como importantes meios para acessar textos relacionados, índices de citação foram inventados. Além disso, quando as coleções eram de uso especial, textos e organização física poderiam ser reorganizados para facilitar os usos de atividades típicas, como em bibliotecas jurídicas e médicas. Embora sistemas de ordem múltiplos tenham sido colocados no topo ou na interseção com a ordem de textos, o modo como os textos físicos eram dispostos na prateleira fornecia o substrato material da profissão de biblioteconomia. Eram os textos que continham informações específicas e de raciocínio que os leitores procuravam. A informação bibliográfica apoiou o achado dos textos que continham a informação substantiva, mas isso não era um substituto para aquilo. Ademais, os documentos físicos forneceram uma lembrança material da proveniência do texto e das pessoas que o escreveram, imprimiram, encadernaram, comercializaram e partilharam os textos. $\mathrm{O}$ texto, assim, forneceu pistas para dar sentido ao que foi inscrito e com que propósito. Mesmo antologias, coleções e reimpressões veiculavam suas próprias histórias sociais. No mundo da imprensa, a interseção das ordens de conhecimento e das ordens de documentos produzidos por pessoas em circunstâncias particulares não era uma questão teórica, era uma questão prática.

A criação, distribuição, armazenamento, acesso e manipulação da informação, de modo digital, tornaram possíveis novos tipos de documentos, novas formas de acesso à informação nos documentos e novos usos para a informação. Muitas dessas formas parecem apagar os traços das ocasiões de criação e da organização e propósitos do documento original. A informação pode ser extraída facilmente em partes; bancos de dados podem ser combinados; interfaces de pesquisa e os algoritmos de busca subjacentes podem reunir materiais heterogêneos de diferentes tipos de redes de comunicação em um formato comum. Além disso, a informação pode ser "lida" e processada por meios digitais com os seres humanos vendo apenas os resíduos finais, 
relatórios agregados ou ações consequentes. Essas possibilidades omitem os documentos originais e seu papel na interação, o que tem guiado o ser humano na atribuição do sentido letrado ao longo de milênios.

\section{INFORMAÇÃO FORA DE DOCUMENTOS?}

Podemos descartar a estrutura de documentos em que temos confiado por tanto tempo? Claro que sempre haverá problemas de sistemas de legados de documentos impressos que têm de ser referenciados de acordo com suas estruturas mais antigas, mesmo que sejam armazenados eletronicamente, a menos que sejam desmontados e reconstruídos no universo inócuo dos dígitos. Entretanto, pelo menos a partir deste momento em diante, podemos simplesmente produzir informações, armazenadas como dados, infinitamente reconfiguráveis, facilmente localizadas como dados? O bibliotecário, então, não deverá mais se preocupar com a estrutura de documentos, mas apenas com os termos de busca e modalidades de extrair os dados atomizados do éter. Assim, estamos no caminho para acabar com textos e documentos, deixando apenas um megasservidor não hierárquico com um banco de dados com todas as informações, a ser consultado com uma interface universal?

Claro que os nossos mecanismos de busca atuais não chegaram lá ainda e, talvez, por boas razões, apesar de indicadores potenciais de uso humano estarem sendo explorados. Mecanismos de busca atuais têm levado em conta a lógica de intertextualidades e as redes de usuários que incorporam muita atribuição de sentido humano e tomada de decisão sobre a seleção de documentos. Metadados, muitas vezes, incluem informação sobre a origem e uso. Até mesmo léxico e semântica são uma consequência da atenção e comunicação entre os usuários. Mais diretamente, as tentativas de desenvolver sistemas de relevância têm tentado combinar características de textos com as características dos usuários (BARRY; SCHAMBER, 1998; BORLUND, 2003), incluindo a exibição visual de projeções individualizadas (BERESI ET AL, 2010 a, b, c). Além disso, os meios de codificação e uso de gênero em pesquisa têm sido explorados (ANDERSEN, 2008; OLIVER ET $a l$, 2008). No entanto, não importa o quão eficientemente a tecnologia de pesquisa possa oferecer textos candidatos a potencial interesse, o usuário humano, finalmente, deve decidir qual das citações oferecidas é digna de se buscar e o que fazer com cada uma. Para melhor atender a esse usuário, gostaria de sugerir que as ordens de textos humanos sejam mais explícitas para anexar as informações contidas em seus usos.

\section{INFORMAÇÃO E CONHECIMENTO DENTRO DE ENUNCIADOS COMO PARTE DAS ATIVIDADES}

Os sociólogos fenomenólogos posteriores a Alfred Schutz (1967), os psicólogos soviéticos culturais posteriores a Lev Vygotsky (1987) e os pragmáticos americanos seguindo George Herbert Mead (1934) compartilham a visão de seres humanos como ação orientada, seres construtores de sentido, usando formas simbólicas socialmente distribuídas. Todos eles oferecem uma resposta para o problema de como podemos criar um entendimento conjunto e ações coordenadas com aqueles que nos rodeiam, apesar da variedade de lugares em que podemos concentrar a nossa atenção e da variedade de interpretações que podemos dar aos atos dos outros. Todas as três abordagens sugerem que moldamos nossos comportamentos e nossos enunciados para que sejam inteligíveis ao outro, por meio da adoção e alinhamento às formas sociais e culturais que estão sendo constantemente produzidas e reproduzidas ao nosso redor. Estas formas moldam as nossas consciências, capacidades cognitivas, identidades sociais e os potenciais para a ação. Mesmo que definamos a nossa individualidade e diferença em nossas comunidades, estamos sempre cercados e imersos no mar de tipos culturais e sociais. É somente pelo aprendizado das formas sociais pelas quais os outros se comunicam e agem que nós descobrimos meios de construir sentido para esses comportamentos, ações e enunciados e de compartilhar ações e enunciados que sejam significativos aos outros. Os significados que construímos decorrem de nossas ações e as nossas palavras estão saturadas de nossas intenções, mesmo quando são retiradas de ações cotidianas, conforme Bakhtin argumentou (1984). Gêneros são formas 
tipificadas de enunciados e o sentido é construído e transmitido a partir do esquema desses gêneros, orientados para a ação ${ }^{1}$.

Mais especificamente, a informação e o conhecimento são construídos em enunciados como parte da ação comunicativa. Enquanto o mundo pode existir sem o nosso falar sobre ele, as informações são elaboradas somente pela nossa ação de criar um mundo simbólico paralelo de representações em resposta às nossas necessidades e aos nossos desejos como seres humanos, mesmo quando criamos e conduzimos máquinas para inscrever, coletar e analisar aquela informação. Essa informação e sua agregação proposital em conhecimento servem, então, para informar e orientar nossas ações, incluindo a construção de representações partilhadas que permitam a coordenação de percepções, metas e ações entre grupos de pessoas mais amplos.

É nos textos que registramos e compartilhamos nossas informações. Na verdade, muitas vezes, reunimos informações para fins de criação de textos para realizar uma ação desejada. Assim, há uma correspondência entre o gênero e o tipo de informação contida nele. Bakhtin caracterizou esta relação como cronotopo - o tempo-lugar típico de um gênero que, então, implica o cenário, os atores e as ações (1981). Assim como contos de fadas ocorrem em reinos em tempos passados e distantes, onde príncipes superam obstáculos de dragões e feiticeiros do mal para ganhar a mão das princesas, assim também os relatórios nacionais de políticas econômicas incluem tendências em empregos, Produto Interno Bruto, endividamento nacional, taxas de juros bem como projeções de crescimento futuro e inflação, de modo a justificar as decisões políticas, tais como ajustes de taxas bancárias. Relatórios psiquiátricos preparados como parte de condenação de réus criminais conteriam um cronotopo muito diferente de informação, olhando para o tempo-espaço de vida e psique do réu e para prognósticos em condições de encarceramento diferentes. Ficaríamos muito surpresos ao encontrar as informações do relatório psiquiátrico do criminoso no documento de política econômica ou vice-versa. $\mathrm{E}$ até mesmo documentos estritamente relacionados podem diferir muito em seus cronotopos com base na finalidade. Um documento de condenação psiquiátrica, por exemplo, conteria informações diferentes de um artigo da revista psiquiátrica no tratamento farmacológico de certas formas de comportamento violento.

Nossas ações diárias atualmente exigem que nos movamos rapidamente entre os vários tipos de informação em vários tipos de documentos. Para comprar um bilhete aéreo internacional, devemos estabelecer os nossos planos com datas precisas, saber mais sobre os nossos destinos, examinar as nossas finanças, obter informações sobre vistos para viagens internacionais e considerar os horários de voos. Devemos reunir números de cartões de crédito, números de passageiro frequente, números de documentos de viagem, e assim por diante, até completar a transação. Cada um desses tipos de informação gerados pelos indivíduos reside em tipos específicos de bancos de dados, criados para realizar tipos específicos de transações. As companhias aéreas criam bases de dados de voos e reservas, de modo a serem capazes de vender passagens e manter o controle de clientes e assentos disponíveis. As companhias aéreas têm criado outro tipo de informação em relação aos incentivos para passageiros que viajam frequentemente para construir uma clientela regular e manter relações com os clientes mais valiosos. Os governos desenvolvem sistemas documentados para controlar as fronteiras e dar proteção aos seus cidadãos fora do país. Os sistemas de cartão bancário e de crédito são projetados para manter e transferir fundos. Somos capazes de navegar e coordenar esses múltiplos sistemas para realizar ações atualmente comuns porque entendemos, até certo ponto, cada um de seus sistemas e entendemos as atividades, os documentos e as informações associadas a cada um (pelo menos no nível do consumidor - um nível diferente é necessário para o balconista da companhia aérea, oficial de fronteira ou bancário).

\footnotetext{
${ }^{1}$ Esta abordagem de gênero foi elaborada em estudos sobre a escrita por Miller (1984) e Bazerman (1988; 1994) e revista por Bawarshi e Reiff (2010) e Bazerman (2011).
} 
Cada um desses tipos de informação tem significados específicos em seu sistema específico. Se os próprios sistemas criam equivalências e conversões, eles devem ser trabalhados por meio de procedimentos ordenados que são muitas vezes dinâmicos em resposta a condições que se alternam. É o caso, por exemplo, de se considerar os sistemas, atualmente em vigor, para ajustar constantemente os preços das passagens em relação a disponibilidades de assentos em cada voo. Nós, como consumidores, precisamos mesclar as informações de vários sistemas, de modo a tomar decisões e cumprir os requisitos de informação de cada um, mesmo que a unidade central em alguns deles seja o dinheiro; em outros, os assentos; em outros, os programas de milhas e em outros, a cidadania. A fim de fazer escolhas de ação razoáveis na intersecção dos sistemas, precisamos de alguma compreensão dos diferentes princípios pelos quais os diferentes tipos de informação são ordenados nos documentos relevantes e da nossa relação com cada uma destas ordens de informação. Em nossa tomada de decisão, podemos também considerar outros tipos de informação, tais como a nossa consciência de eventos especiais que podem influenciar a densidade de tráfego ou modos alternativos de viagem. Interfaces de compra de passagens aéreas, de fato, evoluíram recentemente a fim de fornecer informações de diferentes tipos para permitir ao consumidor construir sentido e tomar decisões (capacidade de procurar outros aeroportos próximos, quadros para a escolha do assento, a capacidade de combinar diferentes conjuntos de voos, comparando melhores preços em dias próximos). Assim, vemos a formação de uma atividade em forma de gênero informativo para facilitar a ação multidimensional de construção do sentido. (Para outro exemplo de quão complexa é a transferência de informações de um sistema de atividade para outro, ver BAZERMAN, 2009).

Até mesmo o conhecimento científico é textualmente construído por meio de processos sociais de argumentação e intercâmbio realizados por meio de trabalhos em seminários, congressos e periódicos. Embora a ciência procure escapar dos caprichos da crença social e da percepção humana limitada para desenvolver uma compreensão empírica do mundo, a sua informação, também, ganha a existência e significação nos mundos sociais de comunicação complexos e tipificados dos gêneros. Mesmo na produção de um único artigo, a informação é buscada, recolhida, selecionada e relatada em agregada relação aos argumentos no artigo ou documento como um todo (BAZERMAN, 1988). Para dar sentido aos artigos e avaliá-los, os cientistas consideram os autores, temas, programas e métodos de pesquisa, em relação aos seus próprios interesses em constante evolução. Eles criam a sua própria teia intertextual de artigos para lançar suas reivindicações em um mundo da comunicação inteligível e partilhado por seus colegas. O conhecimento (na forma de reivindicações/argumentos/documentos) é selecionado como confiável, importante e relacionado ao sistema de conhecimento comunal através de um tipo de codificação que gira de acordo com o sentido, avaliação e escolhas dos autores individuais ao longo do tempo - todos dos quais dependem de documentos e de gêneros (BAZERMAN, 1991). A maioria dos artigos é raramente citada e sai de circulação sem consequências para a construção do conhecimento. Tratar todos os artigos (e cada dado contido em cada um desses artigos) como de igual importância e, igualmente, ligado a outros vai na contramão da maioria dos processos sociais de construção de conhecimento. Até os documentos mais abertamente agregadores, como manuais e livros didáticos, são construídos em leitura e avaliação da literatura, baseando-se largamente na classificação que vem ocorrendo nos artigos e revisões da literatura. Mesmo as temporalidades de documentos têm um sentido diferente. Por isso, se uma afirmação fosse introduzida em um livro didático antes de ter sido resolvida na literatura de pesquisa, a confiabilidade do livro poderia ser posta em questão. Atribuir sentido a um único argumento, oração ou mesmo um dado requer um entendimento sobre o tipo de texto em que aparece, o tipo de investigação em que está envolvido, os métodos usados e o lugar em que se localiza no desenvolvimento da discussão intertextual do campo.

Claro, esses livros, manuais, revisões de literatura e outros documentos agregados fazem muito para estabilizar e partilhar uma visão comum, fornecer pontos de referência comuns e orientar recém-chegados ao campo de estudo. Entretanto, o manual de cinquenta ou até mesmo cinco anos atrás dificilmente pode ser uma fonte de autoridade, mesmo que seja de grande interesse para entender posições teóricas, programas de pesquisas e a história evolutiva da questão. Em vez disso, suas peças de informação precisam ser lidas em 
relação à perspectiva desenvolvida no texto, na história do desenvolvimento do campo e levando em conta os objetivos, propósitos e até patrocinadores da questão. Para ter sentido, torna-se necessária a integridade do texto e a visibilidade da proveniência e dinâmica sócio histórica de onde ele surge.

\section{AS ORDENS DE CONHECIMENTO E AS ORDENS DOS TEXTOS}

As ordens de informação e conhecimento dependem de muitos modos das ordens de textos, tanto textos completos que transmitem um significado integrado quanto gêneros ordenados que transmitam tipos antecipáveis de significados nas ações sociais reconhecíveis. Estes, por sua vez, são dependentes das ordens de sistemas sociais em que as relações e ações sociais são formadas. Em uma perspectiva estruturalista (GIDDENS, 1984), os próprios textos fazem parte da formação e manutenção desses sistemas, e cada novo texto dentro desses gêneros e sistemas de atividade exerce essas atividades socialmente organizadas e sistemas posteriores. A estabilização, a ordem correta e a manutenção desses textos são, muitas vezes, essenciais para as operações e a vitalidade da organização social. Considere, por exemplo, um hospital que depende de seguro, paciente e registros de custos financeiros; regras processuais e diretrizes; planos de ação para pacientes individuais, grupos de trabalho, desenvolvimento de instalações e de gestão; fluxo adequado de documentos entre as hierarquias; informações sobre médicos disponíveis e produtos mais cotidianos (como materiais de limpeza); registros de pedidos; a literatura biomédica mais recente e muitos outros tipos de informações nos documentos. Se qualquer um desses sistemas textuais se tornar desordenado ou a distribuição adequada desses documentos falhar, a organização vai ser prejudicada, talvez, até mesmo, ao ponto de imobilidade e colapso.

\section{COMENTÁRIOS FINAIS}

Como muitas de nossas instituições e formas mais complexas de vida social tornaram-se tão dependentes do acesso e distribuição de um elenco de informações sobre atividades específicas nos documentos que dão sentido à informação, profissionais da ciência da informação têm uma importância especial. Desde os primeiros bibliotecários de Alexandria ou os guardiões das casas de tabuletas na Suméria, os indivíduos criaram princípios ordenadores de arquivamento e indexação de obras para os leitores encontrá-los. Às vezes, esses princípios estavam distantes do verdadeiro uso que pessoas fariam das informações e do sentido que construiriam a partir delas, tais como armazenagem em estantes por data de aquisição ou a arbitrariedade do alfabeto. Às vezes, os princípios ordenadores eram um pouco mais mnemônicos, como incipits ou títulos de livros visto que a impressão facilitava edições distintas de obras. Inovações tentaram lidar com o conteúdo, tais como sistemas baseados em tópicos de indexação ou identificadores de palavraschave. No entanto, em última análise, o usuário experiente tinha que trabalhar com todo o texto e colocá-lo em contextos sociais e intertextuais relevantes para dar sentido à informação que continha. Essa capacidade requeria longo aprendizado, sugerindo a emissão de pareceres de peritos.

As tecnologias digitais, agora, armazenam documentos (bancos de dados tradicionais ou recém-formados) em meios eletrônicos binários ilegíveis por seres humanos até acessados e transformados em formas inteligíveis de representação humana - linguagem, números, gráficos ou similares. Programas sofisticados serão, cada vez mais, capazes de estabelecer rede, relevância, intertextualidade e dados de gênero para selecionar material para usuários individuais, de identificar rapidamente os textos e fragmentos de interesse em potencial, mas o usuário, por fim, terá que construir sentido a partir da informação. De certo modo, estamos todos colocados, atualmente, cada vez mais na posição de pesquisadores de arquivos que têm de aprender a localizar e construir sentido a partir de documentos retirados de suas circunstâncias vigentes, e todos precisamos de meios para que possamos construir a inteligência de arquivamento (YAKEL; TORRES, 2003). Na era digital, o estudioso de arquivamento ainda precisa compreender a estrutura do arquivo, a estrutura dos documentos bem como o papel que os documentos ocupam nas atividades em que 
eles são produzidos e utilizados, a fim de localizar e compreender os documentos que procuram, mas todos faremos isso. A menos que nossas novas tecnologias da informação nos orientem para a estrutura de sistema de dados que armazenem e forneçam acesso à informação, ofereçam-nos pistas para entender o tempo e a situação que, inicialmente, motivou a inscrição da informação, como ela foi usada e as posições da informação no ambiente de representações, nas fontes originais de documentos ou de dados e nos documentos relacionados, torna-se cada vez mais difícil construir sentido do que estamos recebendo como informações fragmentadas ou reprocessadas, construídas em torno de princípios abstratos que não refletem os usos e os significados de que a informação é parte e nem mesmo contêm pistas sobre o processo pelo qual elas foram selecionadas para o nosso uso e entregues a nós. As tecnologias digitais já estão fomentando novos tipos de arranjos sociais e ações, conjuntamente com novos gêneros e até mesmo novos tipos de informação a serem, cronotopicamente, organizadas em documentos dinâmicos. Entretanto, se são feitos para serem usados por seres humanos e para fins humanos, os indivíduos terão de ser capazes de dar sentido a eles, e as tecnologias terão de encontrar formas de apoiar a construção de sentido. Sugiro que os documentos terão uma rigidez maior do que nossas visões poderiam sugerir de partes infinitamente reconfiguráveis.

\section{REFERÊNCIAS}

ANDERSEN, J. The concept of genre in information studies. Annual review of information science and technology, v. 42, n. 1, p. 339-367, 2008.

BAKHTIN, Mikhail. The dialogic imagination. C. Emerson \& M. Holquist, Trans. Austin: University of Texas Press, 1981.

. Problems of Doestoersky's poetics. Minneapolis: University of Minnesota Press, 1984.

BARRY, C.; SCHAMBER, L. Users' criteria for relevance evaluation: a cross-situational comparison. Information processing \& management, v. 34, n. 2/3, p. 219-236, 1998.

BAWARSHI, A.; REIFF, M. Genre: an introduction to history, theory, research, and pedagogy. Fort Collins: WAC Clearinghouse, 2010.

BAZERMAN, C. Shapping written knowledge: the genre and activity of the experimental article in science. Madison: University of Wisconsin Press, 1988.

. How natural philosophers can cooperate. In: BAZERMAN, C.; PARADIS, J. (Eds.). Textual dynamics of the professions. Madison, Wisconsin: University of Wisconsin Press, 1991. p. 13-44.

Systems of genre and the enactment of social intentions. In: FREEDMAN, A.; MEDWAY, P. (Eds.). Genre and the new rhetoric. London: Taylor \& Francis, 1994. p. 79-101.

The languages of Edison's light. Cambridge, MA: MIT press, 1999a.

. Letters and the social grounding of differentiated genres. In: BARTON, D.; HALL, N. (Eds.). Letter writing as a social practice. Amsterdam: Benjamins, 1999b. p. 15-30.

. How does science come to speak in the courts? Citations, intertexts, expert witnesses, consequential facts and reasoning. Law and contemporary problems, v. 72, n. 1, p. 91-120, 2009.

. Genre as social action. In: GEE, J.; HANDFORD, M. (Eds.). The Routledge handbook of discourse analysis. London: Routledge, 2011. p. 226-238.

; ROGERS P. Writing and secular knowledge apart from modern European institutions. In: BAZERMAN, C. (Ed.). Handbook of research on writing. London: Routledge, 2008a. p. 143-156.

Writing and secular knowledge within modern European institutions. In: BAZERMAN, $\overrightarrow{\mathrm{C} .(\mathrm{Ed} .)}$. Handbook of research on writing. London: Routledge, 2008b. p. 157-176.

BERESI, U. C.; KIM, Y; SONG, D.; RUTHVEN, I. Why did you pick that? International journal on digital libraries, v. 11, n. 2, p. 59-74, 2010 a. 
BERESI, U. C.; KIM, Y; SONG, D.; RUTHVEN, I.; BAILLE, M. Relevance in technicolor. Research and advanced technology for digital libraries: lecture notes in Computer Science, 6273, p. 196-207, 2010b.

BERESI, U. C., KIM, Y; BAILLE, M.; RUTHVEN, I.; SONG, D. Colouring the dimensions of relevance. Advances in information retrieval: lecture notes in Computer Science, 5993, 569-572, $2010 \mathrm{c}$.

BORLUND, P. The concept of relevance in IR. Journal of the American Society for Information Science and Technology, v. 54, n. 10, p. 913-925, 2003.

DEWEY, J. Experience and education. New York: Macmillan, 1947.

EDISON, T. Papers: a selective microfilm edition, Parts I \& II. Frederick Maryland: University Publications of America, 1985, 1987.

EISENSTEIN, E. L. The printing press as an agent of change. Cambridge: Cambridge University Press, 1979. GIDDENS, A. The constitution of society. Berkeley: University of California Press, 1984.

GOODY, J. The logic of writing and the organization of society. Cambridge: Cambridge University Press, 1986.

HAVELOCK, E. Preface to Plato. Cambridge: Harvard University Press, 1963.

MEAD, George Herbert. Mind, self, and society. Chicago: University of Chicago Press, 1934.

MILLER, Carolyn R. Genre as Social Action. Quarterly journal of speech, n. 70, p. 151-67, 1984.

OLIVER, G.; KIM, Y.; ROSS, S. Documentary genre and digital recordkeeping: red herring or a way forward? Archival Science, v. 8, p. 295-305, 2008.

SCHMANDT-BESSERAT, D. Before writing. Austin: The University of Texas Press, 1992. When Writing met art: from symbol to story. Austin: The University of Texas Press, 2007.

SCHUTZ, Alfred. The problem of social reality. The Hague: Martinus Nijhoff, 1967.

VYGOTSKY, L. Thinking and speech. N. Minick, Ed. and Trans. New York: Plenum, 1987.

YAKEL, E.; TORRES, D. AI: Archival intelligence and user expertise. The American archivist, v. 66, n. 1, p. $51-78,2003$.

(Texto traduzido) 